\title{
The Evolution of Competing Using Analytics
}

\author{
David J. Fogarty ${ }^{1 *}$ \\ ${ }^{1}$ University of Phoenix, Phoenix, Arizona, USA \\ *David J. Fogarty, E-mail: Dfogarty2@gmail.com
}

Received: September 3, 2016 Accepted: September 7, 2016 Online Published: September 14, 2016

doi:10.22158/rem.v1n2p103 URL: http://dx.doi.org/10.22158/rem.v1n2p103

\begin{abstract}
Competing using analytics is often heralded as a new concept spurned by advances in high-speed computing, the digital age and the internet. However, evidence for using analytics as the basis for gaining a competitive advantage exists much earlier. In his key paper written in 1953 William Edwards Deming wrote that better quality through the use of statistical techniques can lead to a competitive advantage for firms. He also pointed out that for a more effective use of these techniques, top management should not only become familiar with the results of statistical methods; they should study also the problems of organization by which to achieve a wider and more effective use of these methods. Similarly, quality guru Joseph Juran also a Deming contemporary noted that the Japanese learned to compete on quality which is something the Americans did not understand until it was too late and they lost market share.

This paper explores Juran's and Deming's thoughts on competing on quality and evaluates its usefulness and lessons to the modern post-industrial world and one in which BIG DATA is being collected and used by many firms across a variety of industries in an effort to develop a competitive advantage from the use of statistical analysis. It also debunks the common misconception that competing on analytics is something new and novel which represents a call to action for managers in analytically challenged companies since they will now be under investing in function that has been around for over half a century.
\end{abstract}

\section{Keywords}

BIG DATA, Six Sigma, analytics, statistics, hypothesis, testing, TQM, strategy, competition

\section{Introduction}

Lately there has been much written on developing a competitive framework using analytics. Thought leaders in the field such as Thomas Davenport, Peter Bell, Saumitra Bhaduri and David Fogarty have discussed this in great lengths. While it's easy to attribute analytic competition to being a more modern phenomenon this research will demonstrate that $t$ is indeed not a new phenomenon but something which has a history stretching even as far back as the turn of the $19^{\text {th }}$ century. 
William Edwards Deming was known as the Father of modern quality. This scholar practitioner from Iowa was key to the recovery of the post WWII recovery of the Japanese economy and should also be credited for improving the quality of products and services we utilize in the global economy today. Deming looked at quality not only as a statistically based set of tools and principles to achieve better quality products but rather took a more strategic approach as to how a firm and its leaders should view quality. This eventually led to one of his great quotes "in God we trust. All others must bring data". In his key paper written in 1953 Deming wrote that better quality through the use of statistical techniques can lead to a competitive advantage for firms. He also pointed out that for a more effective use of these techniques, top management should not only become familiar with the results of statistical methods; they should study also the problems of organization by which to achieve a wider and more effective use of these methods. Interestingly, Deming was first perceived as a good statistician and not a visionary in quality principles. Deming first went to work for the census bureau as they started to introduce sampling methods into the census process. After the 1940 census. Deming started teaching Statistical Quality Control to inspectors and engineers. However, after WWII General MacArthur appointed Deming to do a population survey in Japan which would have restored his focus on population statistics. However, given his brief interlude working with US industries after the 1940's US Census and his observations of what was needed in Japanese industry he was able to make the more significant contribution to quality and the strategy of applying statistical thinking into firms (Lewis, 2008). I also think the Japanese at the time were much more receptive to these techniques than they would have been at any point in time given they were being led by General MacArthur who was the commander that defeated them in the war. Their US counterparts, however, were starting to ride on the postwar boom in America and had no time to listen to Deming and other quality gurus such as William Juran as their mantra at the time was all about increasing production. With Europe and most of Asia in shambles after WWII they had few serious competitors so there was no major concern over quality. Why improve if America was the predominant economic power with growing domestic economic growth they were saying. While Deming's teaching were revered by quality inspectors and engineers they didn't quite convince top managers responsible for the strategy of the firms. These included industries like steel, autos, appliances and electronics. This created a perfect environment for Deming to guide the Japanese as for Japan this was the only way to effectively compete with US companies in items such as cars and consumer electronics. Moreover, the Japanese managers had nothing to lose. This perfect storm environment enabled Deming to go on to become one of the greatest thought leaders in the modern quality movement would become a colossus of modern management thinking in much of the second half of the $20^{\text {th }}$ century.

Joseph Juran was similar to Deming in terms of his impact on Japanese industry after World War II. Joseph Juran was a thought leader like Deming and is often credit to bringing quality from its statistical origins into a managerial paradigm. His "Quality Control Handbook" is considered to be a bible for Total Quality Management leaders around the globe. Juran lectured than quality management should 
just be left to the shop floor but instead should be embraced by and promoted by management. This paradigm shift brought quality to the strategic level within the organization and thereby enabled it to become a factor in the firm being more competitive. In addition to top management involvement Juran was also known for the definition of quality as fitness for use, the need for widespread quality training and the single project approach to quality improvement.

The hypothesis being explored is that both Deming and Juran were instrumental in being able to take what was once considered the tactical work of individual statisticians and quality engineers and raise it to the strategic level of the firm where firms were able to compete on the basis of analytics and quality. This was accomplished many years before what contemporary academics are describing as a new phase of business analytics primarily being driven by the growth of high speed computing and data collection via digitalization.

\section{Analysis}

The section of Deming's article written in 1953 titled "Management's Responsibility for the Use of Statistical Techniques in Industry" that I would like to first highlight in this research is where Deming discusses competing on analytics. He starts this in his opening sentence where he states: The use of statistical techniques in industry, under competent guidance, results ill greater output, plus the competitive advantage of, better quality, more uniformity, less waste, and greater dependability of product. Later in the article he states... "But the statistical method is more than just a body of techniques. It is not a collection of figures. It is a mode of thought—it provides more reliable answers and sharper decisions especially where competition is keen, where specifications and uniformity are difficult to meet, where the differences between the performances of materials and machines and processes are small, but where a wrong decision may cause heavy losses. Statistical problems must be solved with statistical knowledge; not with knowledge of engineering, production, economics, etc." Note in the previous quote the emphasis Deming makes on where the "competition is keen". My interpretation on this is that Deming thought the competition will also be focusing on quality drivers or some other basis for completion even non analytic in nature. Therefore, in essence Deming was making the case for competing on the statistical method or what we refer to today as competing on analytics. This was either intended to match the competitor in their own pursuits in competing on analytics or put forth a new competitive factor in the marketplace.

Another mention of the competition is on the second page where Deming said "Statistical techniques are needed along the whole line of production, which stretches from raw material to consumer. It is recognized by astute manufacturers that gaps in statistical work, anywhere along the line, mean losses in production, losses in materials, comparative depreciation in quality and uniformity, excessive costs, and ultimate shrinkage of the market". That last statement about shrinking markets is I think where Deming calls to the ultimate impact of poor quality. Later in the article when he provides a summary of the global benefits of the statistical approach to management one of his sections discusses an 
"Improved competitive position through increased production, better quality, better uniformity, belter design, reduced costs". This is again direct evidence pointing to the fact that Deming was indeed thinking about developing a competitive position using analytics in the framework of statistical quality control. This would later be unbundled from TQM and applied in a broader sense responding to the growth of computing power and big data.

The former quotes from the article represent the areas where Deming mentioned competing on analytics or using analytics to create a competitive advantage in the marketplace. The rest of the article focuses on the hiring of good statistical leaders in the organization and training statistical resources in the current time period. This part of the article reinforced the importance Deming placed on performing statistical methods in organizations. These final discussions are directly related to the modern business analytics organizations in firms today, which are separate units with the goal of performing analytics and reporting to senior level leaders in the firm.

Juran also had a similar thought as Deming. For instance Juran (1993) was quoted with the following "While U.S. companies tried to compete with the Japanese on price during the 1950s, the rise in Japanese quality caught them completely off-guard. The American mindset saw the Japanese as copyists rather than innovators-Japan might compete on price but never on quality. What Japan taught us about quality: Making it Management's job — and part of the business plan—led to them having an export edge".

Similarly Juran wrote in his famous Quality Handbook (1999), "Intensified International Competition in Quality. Cities and countries have competed for centuries. The oldest form of such competition was probably in military weaponry. This competition then intensified during the twentieth century under the pressures of two world wars. It led to the development of new and terrible weapons of mass destruction. A further stimulus to competition came from the rise of multinational companies. Large companies had found that foreign trade barriers were obstacles to export of their products. To get around these barriers, many set up foreign subsidiaries that then became their bases for competing in foreign markets, including competition in quality. The most spectacular twentieth-century demonstration of the power of competition in quality came from the Japanese. Following World War II, Japanese companies discovered that the West was unwilling to buy their products—Japan had acquired a reputation for making and exporting shoddy goods. The inability to sell became an alarm signal and a stimulus for launching the Japanese quality revolution during the 1950s. Within a few decades, that revolution propelled Japan into a position of world leadership in quality".

It's very interesting that Juran like Deming was referring to Quality as a basis for competition. Both saw quality as something more strategic than a tactical function located on the shop floor with a few employees. Both saw the great potential to compete in the marketplace based on quality and statistical analysis. 


\section{Discussion}

Moving into the $21^{\text {st }}$ century you have a few authors who have commented about how analytics can not only be used to improve firms in terms of revenue generation or cost savings but also be used as the basis for competition. Three key thought leaders who have researched analytic competition include Thomas Davenport (2007), Peter Bell (2013) and Fogarty and Bhaduri (2016).

Davenport in his famous book "Competing on Analytics" developed the concept that firms have been doing analytics for years but it is only a recent phenomenon that they were actually competing on analytics, that is, using analytics as a basis for competition. Davenport uses the analogy of the alignment of planets to discuss why competing on analytics has become so popular in modern times highlighting such factors as the availability of data and powerful computing resources along with increased global competitive factors.

Peter (2013) discussed how the use of analytics is increasingly commonplace in business given the widespread availability of data and high-speed computing. Moreover, he points out that as a result, it's hard for firms to gain a lasting competitive advantage from analytics. However, he goes on to point out that there are companies that have done just that over time. One of these companies is Wal-Mart who keeps its analytics locked away as a trade secret. Another is when companies recognize that sometimes the data they have is more valuable than the actual algorithms themselves and the company works to protect their data. Bell (2013) uses the example of American Airlines and their scheduling algorithms which were made available to other airlines in order to save in airline crew costs. The algorithms were recognized to be fairly straight forward, however, the vast scheduling data that American Airlines had amassed was the real value in this process.

Another way to sustain an analytics advantage discussed by Bell (2015) is for firms to become truly data-driven. By this he means analytics are embedded in the corporate culture from the CEO and down. Examples he cites include Amazon and FEDEX.

Fogarty and Bhaduri (2015) discussed advanced analytics as a way for firms to create a competitive advantage. This discussion evolves from advanced analytics specific to each program that a firm executes all the way to creating a common currency within the Enterprise with a customer lifecycle value model which measures and predicts the overall profitability of individual customers. The Capital One approach is highlighted in which the firm competes on the basis of marginally better models. In Capital One's case this is better credit scores which enable Capital One to select more customers which are identified as subprime by competitors but will prove to be profitable for Capital One. They also utilize customer lifetime value to determine what a customer could be worth and compare with their current performance under the implicit assumption that they have better modeling capabilities and therefore know something about customers and prospects which their competitors do not. Another example is Netflix which competes on the basis of creating better movie preference algorithms so subscribers will continue to watch Netflix shows versus other media outlets. Combining advanced analytics with an alternative and more convenient distribution platform enabled Netflix to severely 
disrupt their competition to the extent that their original competitors such as Blockbuster video are no longer in business. Customers instead of walking into retail physical Blockbuster stores can now save time by logging into Netflix and having their movie and TV show preferences highlighted for them thus saving valuable time and resources. They also changed the business model at the same time by not requiring customers to pay annoying late charges. All in all this new model was not only convenient but saved money for customers who now pay a lower fixed cost per month for their entertainment. It was also more efficient since Netflix did not have to carry a physical inventory of movies and have brick and mortar retail outlets.

Interestingly, none of the scholars above explicitly acknowledge the earlier thought leadership by Dr. Deming and William Juran which I think is evidence pointing to a gap in the current academic thought on the topic. Some may dismiss this as more geared toward modern service business but this is not the case as Deming (1953) made it clear in his article that quality improvement techniques should be applied to all firms both manufacturing and services. The following is a quote from Deming which makes this point very clear:

"By industry we must include practically every kind of production or service. A public utility company is included, a hotel, a restaurant, a laundry. Even a university is included: it takes in raw material, processes and inspects it, and turns out a product", Deming (1953).

So based on the quote above it is apparent that Deming was obviously thinking beyond manufacturing and even could foresee the usefulness of quality management and a data driven process in the service industries.

Similarly, Juran also discussed the application of quality to different industries in his Quality Handbook (1999) where in addition to outlining quality improvement initiatives across different functions within a firm he has also include specific chapters (by various authors including himself) devoted to the Technology, Automotive, Travel and Hospitality, Government Services, Healthcare and Financial Services industries.

Davenport (2007) admitted that competing on analytics was not entirely new and that some firms such as credit cards and financial services have been using analytics as the basis for competition for many years. What Davenport was referring to makes sense from his examples is in the post-industrial world. Davenport created an analytic maturity model known as the Analytic Delta Model. This model definitely has some components which were similar to those suggested by Deming in the mid-century such as measuring the extent of executive support for analytics and the importance of hiring and training the right analysts to be able to conduct analytics and managers to lead the implementation of the analytics throughout the enterprise.

The overall goal of this research is to point out that competing on analytics goes back even further as evidenced by what Deming and Juran both point out in their earlier writings (some of which span back to mid-century) that firms can compete on the basis of quality. This thought process may even go further back than Deming and Juran as explained in Fogarty (2016) who evaluated the achievements of 
William Sealy Gosset, the founder of the Student's T-Test at the turn of the nineteen century. Apparently at the time Guinness Brewery was hiring statisticians and other types of quantitative researchers in order to improve the quality and consistency of their beer and its ingredients. Gosset couldn't publish under his own name as Guinness prohibited this practice in an effort to protect the disclosure of trade secrets. Gossett therefore published his research under the pseudo name "Student". Interestingly, just about all undergraduates in the US are required to take an introductory statistics class and amazingly many students of the students learning statistics for the first time never learn about the background of this strange name used by the creator of this fundamental statistic. However, the story behind it is a fascinating look at competing with analytics. Even the fact that Guinness forced Gosset to use a pseudo name is evidence that the firm was concerned about the competition getting possession of their trade secrets in the form of intellectual property. As a side note this is a great teaching opportunity for faculty to be able to bring the T-statistic to life especially with a comment on Guinness Brewery which most college students can relate to especially around St. Patrick's Day. Interestingly, Hotelling (1930) wrote that two other two other analysts from the Guinness published statistical work under assumed names: Sophister and Mathete. I think it was very progressive for Guinness breweries to have the inclination to disseminate important knowledge and at the same time protect the application of it to their own business process as a trade secret. Many companies today can learn from this example and attempt to use their developments to make a contribution to knowledge versus keeping everything a trade secret. Guinness continues to get public relations benefits of their efforts over a hundred years later. Knowledge lasts forever as opposed to the more ephemeral brand campaigns we see today.

Another example is Frank Wilcoxon (1945) who as a group leader of the insecticide and fungicide laboratory of the American Cyanamid Company in Stamford, Connecticut in 1943. Wilcoxon started out as a chemist but later in his career his interest and expertise in the application of statistics to creating chemical products grew. In 1950 he transferred to the Lederle Laboratories Division of Cyanamid where he developed and led a statistical consulting group which represented one of the first of its kind and is considered a frontrunner for the modern business analytics organization. Wilcoxon was also a scholar practitioner who taught at various institutions including the Department of Statistics at Florida State University in Tallahassee and at the Brooklyn Polytechnic Institute. Wilcoxon's courses were known to be interesting to students in statistics as he was able to blend his strong practitioner experience along with the academics. Wilcoxon's statistical research focused on rapid easy statistical methods. In particular, he was interested in ranking methods resulting in his seminal paper, Wilcoxon (1945), in which he introduced both the signed ranks and rank-sum tests which are regarded as cornerstone nonparametric hypothesis testing procedures. This was published with Wilcoxon under the affiliation of American Cyanamid Company and this research focusing on improving the chemistry related to fungicides, fumigants, and insecticides combined with the statistics team Wilcoxon managed within this organization represented a version of competing on analytics. 
The current analytic thought leaders are definitely on the right track when it comes to the concept of competing on analytics. However, we must realize that the idea is not as novel and contemporary as we think and instead has just shifted to being important around the type of analytics we do today. Doing better analytics to fuel the development of quality products was just as important for the Japanese and Korea to gain a market share for their products in the 1970's and for the US to revive its failing industries in the 1980 's. It was also just as important for Guinness to be able to become the premier brewer of malt beverages at the turn of the century.

This paper explored Deming and Juran's original works and evaluated their usefulness and lessons to the modern post-industrial world and one in which BIG DATA is being collected and used by many firms across a variety of industries. It also recognizes that competing on analytics must shift and evolve with the nature of industry. Somehow scholars today are not easily able to bridge the gap between what Deming and Juran talked about and their observations of competing on analytics in their own domain specific research environment. They are spending much time focusing on new knowledge creation or applications when in fact this knowledge existed in the past and can be leveraged in the future. For example, Davenport points out that one of the key drivers to competing on analytics is Leadership. Interestingly this is also discussed by Deming and is in fact even represented in the title of the paper! Similarly, Juran wrote in his Quality Handbook that for successful quality driven-companies one of the success factors is: "Upper managers took charge of managing for quality by recognizing that certain responsibilities were not delegable - they were to be carried out by the upper managers, personally. These responsibilities included; serving on the quality council; establishing the quality goals; providing the needed resources; providing quality-oriented training; stimulating quality improvement; reviewing progress; giving recognition; and revising the reward system". As mentioned above this was also discussed by Bell (2015) when he called for analytics to be embedded into the organization from the CEO downward in order for a firm to be able to sustain their analytic advantages.

\section{Conclusions}

The importance of this research is to ensure we have a continuum of focus on embedding analytics within an organization. With analytic-driven competitors such as Uber, Google Drive and Netflix causing disruption in the marketplace it's important for all managers to embrace analytics not only as an offense but also to build defensive capabilities. Managers must not fall into the trap of thinking that competing on analytics is new and that they need to "sell" it into an organization. Instead, they must treat it as business as usual and devote a portion of their management bandwidth and budget to engaging in analytic activities. What better way if a business is not adopting these techniques to claim that businesses have been doing this since the turn of the century. Furthermore, one can claim that it was firmly established through Deming and his contemporaries in the 1950's. Using this logic top managers not adopting an analytic driven approach can be accused of being "behind the times" rather than adopting something new. Of course, sometimes it's better to claim something is new and when 
this is the case seeing how Deming and his contemporaries especially Juran handled the transition into analytics driven decision making will be helpful for managers to integrate analytics within their own organizations. There is also an opportunity to bridge the gap on the industrial and post-industrial techniques. Fogarty (2014) discusses the natural progression in integrating Lean Six Sigma with advanced analytics, including both structured and unstructured data under the BIG DATA category, and treating them both as complementary activities in his recent paper. I also think with all the focus on moving manufacturing overseas to places like China there are application to apply the improved Lean Six Sigma techniques to make their manufacturing more efficient. Many of these factories trade on cheap labor as opposed to efficiency. Becoming more efficient may create opportunities to increase margins and wages at the same time. This will greatly help the Chinese in achieving their goal of converting from an export economy to one based on internal consumption. It is reminiscent of when Deming was sent over to Japan under the invitation of General MacArthur to improve the efficiency and help rebuild the postwar Japanese industry. This would serve importers like the US by increasing the quality and lowering the cost of acquiring raw material or selling retail goods. Earlier related studies just reviewed a single case (Deming's) While this study expanded on cases via the inclusion of the Juran writings and subsequently reinforced the earlier findings the fact still remains that we were only able to review a few cases (including Deming and Juran's) on competing with analytics. Suggestions for further research would be to create a comprehensive body of historical research work around the concept of competing on analytics. With this one would be able to create a better framework for how the discipline has evolved over time and where it may be heading in the future.

\section{References}

Bell, P. (2013). Creating Competitive Advantage Using Big Data. Ivey Business Journal Online, 1-6.

Bell, P. (2015, Spring). Sustaining an Analytics Advantage. MIT Sloan Management Review, 1-4.

Davenport, T., \& Harris, J. G. (2007). Competing on Analytics: The New Science of Winning. Harvard Business ScSchool Press.

Deming, W. E. (1953). Management's Responsibility for the Use of Statistical Techniques in Industry. Advanced Management, 18, 8-12.

Fogarty, D. J. (2014). Lean Six Sigma and Data Analytics: Integrating Complementary Activities. Global Journal of Advanced Research, 2(2), 472-480.

Fogarty, D., \& Bhaduri, J. S. (2016). Advanced Business Analytics: Essentials for Developing a Competitive Advantage.

Fogarty, D. J. (2016). From Suds to Derivatives: The History of Analytics in Business (Unpublished Manuscript).

Hotelling, H. (1930). British Statistics and Statisticians Today. Journal of the American Statistical Association, 25, 186-190. http://dx.doi.org/10.1080/01621459.1930.10503118 
Juran, J. M. (1993). What Japan Taught Us About Quality; Making it Management's Job—and Part of the Business Plan—Led to an Export Edge. The Washington Post.

Juran, J. M. (1999). Juran's Quality Handbook. The McGraw-Hill Companies, Inc.: New York.

Wilcoxon, F. (1945). Individual Comparisons by Ranking Method. Biometrics Bulletin, 1(6), 80-83.

http://dx.doi.org/10.2307/3001968 